\title{
LETTER
}

\section{Using pulse pressure variation or stroke volume variation to diagnose right ventricular failure?}

\author{
Frederic Michard', Guy Richards², Matthieu Biais ${ }^{3}$, Marcel Lopes ${ }^{4}$ and Jose Otavio Auler ${ }^{5}$ \\ See related research by Daudel et al., http://ccforum.com/content/14/3/R122
}

We read with interest two recent studies suggesting that pulse pressure variation (PPV) is not an accurate predictor of fluid responsiveness in subjects with pulmonary hypertension $[1,2]$.

We agree that PPV and stroke volume variation (SVV) may not work in patients with right ventricular (RV) failure. Indeed, when PPV and SVV are related to an inspiratory increase in RV afterload (and not to a decrease in RV preload), they cannot serve as indicators of fluid responsiveness [3].

This is indeed a limitation but can also be seen as useful information for clinicians who do not have an echo probe on the ends of their fingers. PPV and SVV are now available on virtually all bedside and hemodynamic monitors. These parameters have been shown to be very useful for predicting fluid responsiveness in many patients with an arterial line who are mechanically ventilated [3]. When part of goal-directed strategies, these parameters have also been shown able to improve patient outcome $[4,5]$. As a result, PPV and SVV are now widely used by clinicians in the decision-making process regarding fluid therapy. In this context, the lack of response to a volume load while PPV or SVV is high should be seen as an indicator of RV dysfunction, and should trigger an echocardiographic evaluation to confirm the diagnosis and to understand the underlying mechanisms.

In other words, we believe PPV and SVV may actually help clinicians to diagnose quickly and treat properly shock states related to RV failure!

\section{Authors' response}

Stephan M Jakob and Jukka Takala

We agree with Michard and colleagues that failure to respond to fluid loading despite PPV may indicate RV failure. We refer to the commentary of Sheldon Magder where he discusses the various factors that can influence PPV [6]. We also agree with Michard and colleagues that PPV and SVV may be reasonable to guide volume therapy in such conditions where simple hypovolemia in patients undergoing controlled mechanical ventilation is the main factor influencing PPV - typically perioperatively in patients without confounding cardiopulmonary abnormalities. In contrast, the usefulness of PPV and SVV in the intensive care unit is at best limited due to the many factors that influence heart-lung interactions [6]. These factors include the presence of spontaneous ventilatory efforts, irregular heart rhythm, ventilator settings

\footnotetext{
*Correspondence: michard.frederic@free.fr

'Critical Care, Edwards Lifesciences, 70 Route de I'Etraz, 1260, Nyon, Switzerland Full list of author information is available at the end of the article
}

different from those in the original studies $[7,8]$, cardiovascular drugs [8], pulmonary artery hypertension and impeding or manifest right heart failure $[1,2]$ - one or several of these factors may be present even in the majority of intensive care unit patients.

PPV has been advocated to indicate volume responsiveness - in part in order to avoid unnecessary fluid loading. In the particular case of RV failure, PPV may induce the clinicians to do exactly what should be avoided - to load the already overloaded right ventricle. On top of this, we fully endorse Magder's opinion that even if PPV does predict volume responsiveness, it does not mean that the patient actually needs volume or that volume is the best management choice [6].

\section{Abbreviations}

PPV, pulse pressure variation; RV right ventricular; SVV, stroke volume variation.

\section{Competing interests}

FM is a director at Edwards Lifesciences and a co-inventor on patent US20070179386. The Department of Intensive Care Medicine has, or has had in the past, research contracts with Abbott Nutrition International, B. Braun Medical AG, CSEM SA, Edwards Lifesciences Services GmbH, Kenta Biotech 
Ltd, Maquet Critical Care AB, Omnicare Clinical Research AG, and Orion Corporation; and research \& development/consulting contracts with Edwards Lifesciences SA and Maquet Critical Care AB. The money is/was paid into a departmental fund; no author receives/received individual fees.

\section{Author details}

'Critical Care, Edwards Lifesciences, 70 Route de l'Etraz, 1260, Nyon, Switzerland. ${ }^{2}$ Charlotte Maxeke Hospital, Johannesburg, South Africa. ${ }^{3}$ Department of Anesthesia \& Critical Care, Pellegrin Hospital, 33076, Bordeaux, France. ${ }^{4}$ Anesthesia \& Critical Care, Santa Casa de Misericordia, 164 rua Santa Casa, 37900-020, Passos, Brazil. ${ }^{5}$ Anesthesia \& Critical Care, INCOR, 44 Dr Eneas de Carvalho Aguiar Avenida, 05403-000, Sao Paulo, Brazil.

Published: 24 November 2010

\section{References}

1. Daudel F, Tüller D, Krähenbühl S, Jakob SM, Takala J: Pulse pressure variation and volume responsiveness during acutely increased pulmonary artery pressure: an experimental study. Crit Care 2010, 14:R122.

2. Wyler von Ballmoos M, Takala J, Roeck M, Porta F, Tueller D, Ganter CC, Schröder R, Bracht H, Baenziger B, Jakob SM: Pulse-pressure variation and hemodynamic response in patients with elevated pulmonary artery pressure: a clinical study. Crit Care 2010, 14:R111.

3. Michard F: Changes in arterial pressure during mechanical ventilation.
Anesthesiology 2005, 103:419-428.

4. Lopes MR, Oliveira MA, Pereira VO, Lemos IP, Auler JO, Jr, Michard F: Goaldirected fluid management based on pulse pressure variation monitoring during high-risk surgery: a pilot randomized controlled trial. Crit Care 2007, 11:R100.

5. Benes J, Chytra I, Altmann P, Hluchy M, Kasal E, Svitak R, Pradl R, Stepan M: Intraoperative fluid optimization using stroke volume variation in high risk surgical patients: results of prospective randomized study. Crit Care 2010, 14:R118.

6. Magder S: Further cautions for the use of ventilatory-induced changes in arterial pressures to predict volume responsiveness. Crit Care 2010, 14:197.

7. De Backer D, Heenen S, Piagnerelli M, Koch M, Vincent JL: Pulse pressure variations to predict fluid responsiveness: influence of tidal volume. Intensive Care Med 2005, 31:517-523.

8. Kim HK, Pinsky MR: Effect of tidal volume, sampling duration, and cardiac contractility on pulse pressure and stroke volume variation during positive-pressure ventilation. Crit Care Med 2008, 36:2858-2862.

\section{doi:10.1186/cc9303}

Cite this article as: Michard F, et al:: Using pulse pressure variation or stroke volume variation to diagnose right ventricular failure? Critical Care 2010,

$14: 451$ 